\title{
Inventário arbóreo e diagnóstico da ocorrência de cupins em duas praças de Santarém, Pará
}

Praças são áreas públicas com função social, ambiental e econômica, apresentando árvores e infraestrutura urbana em sua composição, as quais proporcionam sensação de bem-estar a seus frequentadores. Contudo, para que benefícios sejam proporcionados, é necessário a realização de um minucioso planejamento para a criação de espaços verdes urbanos e uma perfeita coexistência entre a vegetação e os elementos urbanísticos. Nesse sentido, o presente trabalho teve por objetivo realizar um inventário arbóreo do tipo censo, de caráter quali-quantitativo para conhecer a composição florística e diagnosticar a fitossanidade das árvores de duas praças no município de Santarém, Pará. Sendo realizada a (a) identificação botânica das espécies e analisada a (b) fenologia do indivíduo, (c) posição e sanidade da copa, fuste e raiz, (d) existência de conflitos com a fiação elétrica, (e) necessidade de manejo e (f) diagnóstico visual da ocorrência de cupins. Foram registradas 18 árvores na Praça das Flores (praça 1), sendo a sapupira a mais frequente, e 6 indivíduos na Praça Nossa Senhora das Graças (praça 2), sendo o nim a espécie mais comum. Na avaliação qualitativa apenas a Praça 1, apresentou fuste com inclinação e parasitas nas copas das árvores. Quanto as raízes, foi observado afloramento contido na praça 1 e danos à infraestrutura com rachaduras nas calçadas devido ao afloramento de raízes na praça 2 . 0 fuste em ambas as praças se apresentavam saudáveis, sem ocorrência de parasitas. Em relação ao diagnóstico de cupins, ambas as praças não apresentavam sinais visíveis de ataque.

\section{Arborical and diagnostic inventory of coupins occurrence in two Santarém squares, Pará}

\begin{abstract}
Squares are public areas with social, environmental and economic function, presenting trees and urban infrastructure in their composition, which provide a sense of well-being to their regulators. However, for the benefits to be proportionate, it is necessary to carry out a thorough planning for the creation of urban green spaces and a perfect coexistence between the vegetation and the urbanistic elements. In this sense, the present study aimed to carry out a tree inventory of the census type, of Quali-quantitative character to know the floristic composition and to diagnose the plant health of trees of two squares in the municipality of Santarém, Pará. Being performed the botanical identification of the species and analyzed the (b) phenology of the individual, (c) position and sanity of the canopy, fuste and Root, (d) Existence of conflicts with the electrical wiring, (e) Need for Management and (f) visual diagnosis of the occurrence of Termites. Eighteen trees were registered in Praça das Flores (Square 1), with Sapupira being the most frequent, and 6 individuals in Piazza Nossa Senhora das Graças (Square 2), the neem being the most common species. In the qualitative evaluation, only square 1 presented a slope and parasites in the tree tops. As for the roots, the outcrop was observed in square 1 and damage to the infrastructure with cracks in the sidewalks due to the root outcrop in square 2 . The fuste in both squares were healthy, without occurrence of parasites. Regarding termite diagnosis, both squares did not present visible signs of attack.
\end{abstract}

Keywords: Urban arborization; Public space; Plant health; Termites.

Topic: Planejamento, Gestão e Políticas Públicas Ambientais

Received: 13/07/2019 Approved: 20/10/2019

Reviewed anonymously in the process of blind peer.

\author{
Mayra Piloni Maestri (iD \\ Universidade Federal Rural da Amazônia, Brasil \\ http://lattes.cnpq.br/2687102042811310 \\ http://orcid.org/0000-0002-8936-952X \\ mayrapmaestri@hotmail.com \\ Sara Freitas de Sousa (iD \\ Universidade Federal do Oeste do Pará, Brasil \\ http://lattes.cnpq.br/0444579834038751 \\ http://orcid.org/0000-0002-1305-8514 \\ sara freitas stm@hotmail.com
}

Danielle das Flores de Sales

Universidade Federal do Oeste do Pará, Brasil

http://lattes.cnpq.br/1010553882260221

danielleflores@gmail.com

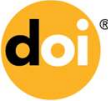

DOI: 10.6008/CBPC2237-9290.2019.003.0004

Referencing this:

BRAGA, B. A.; RODRIGUES, E. S.; SALES, D. F.; MAESTRI, M. P.; SOUSA S. F.. Inventário arbóreo e diagnóstico da ocorrência de cupins em duas praças de Santarém, Pará. Natural Resources, v.9, n.3, p.33-39, 2019. DOI: http://doi.org/10.6008/CBPC2237-9290.2019.003.0004 


\section{INTRODUÇÃO}

As praças são consideradas espaços públicos e de relevância para as cidades, e merecem atenção especial, pois proporcionam lazer e ainda contribuem na inserção da vegetação no meio urbano (OLIVEIRA et al., 2011). As características da arborização têm papel fundamental nos espaços urbanos, visto que sua distribuição influencia diretamente na redução de temperaturas, criando condições agradáveis e confortáveis nos centros urbanos (OLIVEIRA et al., 2013).

A arborização e vegetação presentes nas praças possuem funções importantes como fornecer sensações de equilíbrio e bem-estar para seus usuários e frequentadores (TAKEDA et al., 2013). No entanto, de acordo com Barbosa et al. (2015), para que uma arborização seja eficiente e tenha o máximo de benefícios a população, deve-se apresentar em sua composição uma diversidade de espécies. Além de constante monitoramento e adequados tratos silviculturais, que vão desde a produção de mudas de alta qualidade à manutenção com podas regulares em indivíduos adultos (SCHALLENBERGER et al., 2010).

Para que a arborização proporcione todos seus benefícios, a mesma deve ser feita através de um Plano de Arborização Urbana, para que sejam evitados problemas como, queda de árvores, quebra de calçadas e conflitos com rede de energia, podendo causar acidentes (CARVALHO et al., 2016). Dessa forma, faz-se necessário a realização de inventário da floresta urbana, uma vez que o levantamento e avaliação de informações quali-quantitativas são essenciais para identificar as condições das árvores no meio urbano, sua fitossanidade, necessidade de intervenções silviculturais e ainda localizar áreas potenciais de risco (BENATTI et al., 2012). Em Schush (2006), a importância de se fazer inventários arbóreos em zonas urbanas é dado destaque, visto que através dessas atividades os órgãos administrativos e ambientais competentes detêm de conhecimentos da diversidade e o comportamento de espécies, incidências de pragas e doenças entre outros fatores de manutenção.

Vale ressaltar que através de inventários, também pode-se diagnosticar ataques de organismos degradadores de madeira, por meio de inspeção visual. Os principais agentes degradadores biológicos da madeira são: insetos, fungos, moluscos, crustáceos e bactérias (REMADE, 2013). Organismos biodeterioradores apresentam características que os tornam capazes de utilizar a madeira como substrato, abrigo e alimento (ELEOTÉRIO et al., 2000). Dentre os organismos frequentes na floresta urbana destacamse os cupins ou térmitas (insetos) que, segundo Sousa (2016), são os principais agentes biológicos de degradação da madeira ao serem capazes de digerir a celulose.

Os térmitas podem ser divididos em três grupos: cupins subterrâneos, cupins de madeira úmida e cupins de madeira seca (MENDES, 1988). Dentre estes, os cupins subterrâneos são mais conhecidos por causarem maiores danos a madeira (SOUSA, 2016). De acordo com Amaral (2002), cupins podem atacar árvores vivas, sendo que o inicia pelos tecidos mortos que vão progredindo até chegar a porção viva da mesma, podendo acarretar na morte precoce do indivíduo arbóreo. Assim, este trabalho teve como objetivo realizar o inventário arbóreo quali-quantitativo e diagnosticar ataque de cupins em 2 praças do município de Santarém-PA, de forma a fornecer subsídios ao planejamento e manutenção desse setor no município. 


\section{MATERIAIS E MÉTODOS}

A cidade de Santarém, se localiza no Baixo Amazonas, na região Oeste do Pará, é banhada pelos rios Tapajós e Amazonas (SANTARÉM, 2018), possui uma população estimada de 302.667 pessoas (IBGE, 2018). O inventário das praças ocorreu no mês de novembro de 2018 , sendo realizado um censo que abrangeu duas praças relativamente próximas, Praça das Flores, no bairro Aeroporto Velho e Praça de Nossa Senhora das Graças, no bairro Santa Clara (figura 1).

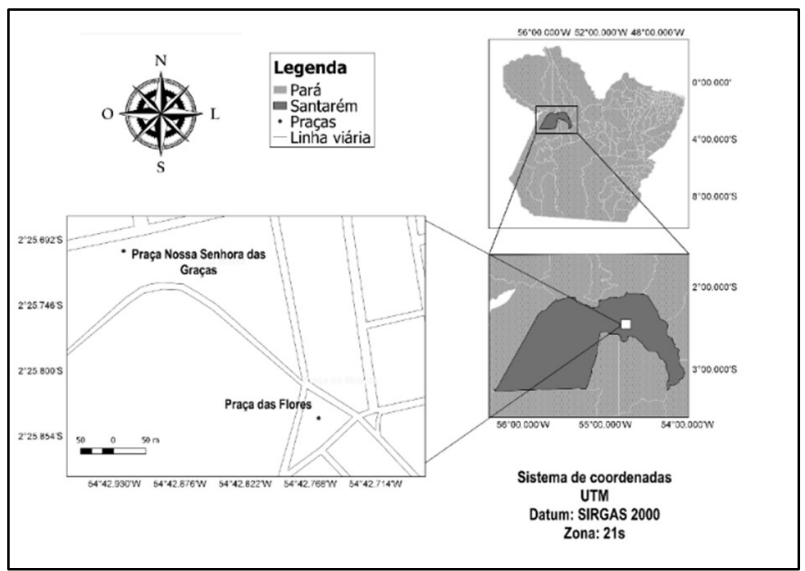

Figura 1: Mapa de localização das praças dentro da cidade de Santarém, Pará.

O inventário do tipo senso foi realizado no mês de dezembro de 2018 com o auxílio de planilhas estruturadas pelo Projeto Floresta Urbana, parceria entre a Universidade Federal do Oeste do Pará (UFOPA), Secretaria Municipal de Meio Ambiente de Santarém (SEMMA), Instituto de Desenvolvimento Florestal e da Biodiversidade do Estado do Pará (IDEFLOR-BIO) e Secretaria Municipal de Agricultura e Pesca (SEMAP).

Para análise da florística das praças foi realizado registro fotográfico dos exemplares arbóreos para auxiliar na sua identificação junto a informações científicas publicadas e, para sua correta identificação, contou com auxílio de um profissional para botânico do Laboratório de Sementes Florestais (LSF), localizado na Universidade Federal do Oeste do Pará (UFOPA), campus Santarém.

As informações qualitativas da vegetação foram adicionadas à uma planilha, onde se analisava a posição e a sanidade da copa, fuste e raiz, além do potencial para alcançar a fiação, a necessidade de manejo e a fenologia. A classificação se dava da seguinte forma: Posição de Copa: Normal (0); Inclinada em direção à rua (1); Sanidade de Copa: Sem problemas (0); Com cupins (1); Com parasitas (2); Presença de podridão (3); Posição de Fuste: Sem inclinação (0); Inclinação em direção à rua (1); Sanidade de Fuste: Sem problemas (0), quando o fuste não apresentava nenhum tipo de infestação; Cupim (1), quando esses organismos estavam presente o fuste; Podridão (3), quando se notava que o fuste apresentava sinais de podridão; Posição de Raiz: Sem afloramento (0); Sem afloramento com rachadura (1); Afloramento contido sem prejuízo (2); Afloramento com prejuízos à calçada (3); Sanidade de Raiz: Sem problemas (0), quando a raiz não apresentava nenhum dano; Raiz cortada(1), quando esta apresentava ferimentos; Apodrecimento (2), quando as raízes apresentam sinais de podridão; Estrangulada (3), quando estavam sendo estranguladas; Manejo: Sem necessidade manejo (0); Necessidade de Poda (1); Substituição do indivíduo (2); Remoção do indivíduo (3). 


\section{Sanidade das árvores}

Realizou-se o diagnóstico das árvores quanto a sanidade conforme Amaral (2002), onde observou-se a ocorrência de cupins, por meio da análise visual, em que a análise se deu por meio de vestígios de térmitas na superfície do tronco, casca e entre casca, na base da árvore junto ao solo, além do diagnóstico da intensidade de ataque detecção do início do ataque.

\section{RESULTADOS E DISCUSSÃO}

\section{Espécies arbóreas}

Nas duas praças estudas foram inventariadas, 24 árvores, sendo 18 destas localizadas na Praça das Flores e 6 na Praça de Nossa Senhora das Graças. Na Praça das Flores, foram encontradas cinco espécies diferentes: alvineira (Andira parvifolia Mart. ex Benth.), ipê rosa (Handroanthus heptaphyllus), mangueira (Mangifera indica L.), oiti (Licania tomentosa Benth.) e piquiá (Caryocar brasiliense). Já na Praça de Nossa Senhora das Graças, foi encontrado três espécies: nim (Azadirachta indica), alvineira (Andira parvifolia Mart. ex Benth.) e oiti (Licania tomentosa). Na primeira praça, a espécie de maior frequência foi a alvineira com 50\% dos indivíduos encontrados e na segunda praça foi o nim com 67,7\%, como mostra a tabela 1 e 2.

Para Tische et al. (2014) a frequência de uma única espécie não deve ultrapassar 15\%, uma vez que a diversidade de espécies é essencial para a segurança sanitária da arborização, pois reduz o número de perdas por pragas e doenças (MILANO et al., 2000). No entanto, nas duas praças avaliadas foram encontradas espécies com frequência maior do que recomentado na arborização urbana.

Tabela 1. Espécies arbóreas identificadas na Praça das Flores.

\begin{tabular}{|l|l|l|l|}
\hline Nome científico & Nome vulgar & $\mathbf{N}^{\circ}$ de indivíduos & Frequência (\%) \\
\hline Andira parvifolia & Alvineira & 9 & 50,00 \\
\hline Handroanthus heptaphyllus & Ipê rosa & 3 & 16,65 \\
\hline Mangiferasp. & Mangueira & 1 & 5,56 \\
\hline Licania tomentosa & Oiti & 1 & 5,56 \\
\hline Caryocar brasiliense & Piquiá & 1 & 5,56 \\
\hline & & & \\
\hline Total & & 18 & 100,00 \\
\hline
\end{tabular}

Tabela 2. Espécies arbóreas identificadas na Praça de Nossa Senhora das Graças.

\begin{tabular}{|l|l|l|l|}
\hline Nome científico & Nome vulgar & $\mathbf{N}^{\circ}$ de indivíduos & Frequência (\%) \\
\hline Azadirachta indica & Nin & 4 & 66,70 \\
\hline Licania tomentosa & Oiti & 1 & 16,70 \\
\hline Andira parvifolia & Alvineira & 1 & 16,70 \\
\hline Total & & 6 & 100,00 \\
\hline
\end{tabular}

Em Lindenmaier et al. (2008), relatou-se que é expressivo a utilização de espécies leguminosas na arborização urbana. Esse comportamento também foi encontrado na Praça 1 deste estudo onde 50\% das espécies que compõem a praça são da família Fabaceae, corroborando com os encontrados na literatura (GOMES et al., 2016; FREITAS et al., 2015; SILVA et al., 2016). A família Fabaceae possuem características favoráveis ao meio urbano que estão associadas a sua alta frequência na arborização das cidades, como suas folhas que garantem sombra no verão e ao caírem geram luminosidade no inverso, além dos aspectos estéticos da floração. 


\section{Avaliação Qualitativa}

$\mathrm{Na}$ Avaliação qualitativa, em ambas as praças as árvores apresentaram boa posição de copa (normal), a exceção da praça 1, em que havia uma árvore posicionada em direção à rua. Gomes et al. (2016), ao realizarem o inventário em uma praça em Macapá (AP), encontraram resultados semelhantes, a maior parte dos indivíduos amostrados não apresentavam copas projetadas sobre a rua, os autores ainda ressaltam essa situação é considerada boa, pois árvores com essas características não impedem a visualização necessária dos veículos, placas de sinalização e transito de pedestres nas praças.

Quanto à sanidade das copas, na Praça 1, foi detectado a presença de parasitas em $38,88 \%$ das árvores, estando as demais sem nenhum tipo de problema. Vale ressaltar que os parasitas observados se encontravam nos indivíduos da espécie alvineira, a qual era a mais frequente na praça, e devido a esse fator, a propagação dos agentes xilófagos possivelmente pode ter sido maior. Silva et al. (2016), encontraram em uma praça em Natal, resultados superiores, $77 \%$ das espécies amostradas apresentaram problemas de fitossanidade. Já na praça 2, por sua vez, nenhuma das espécies inventariadas continha a presença de cupins ou parasitas, estando todas saudáveis.

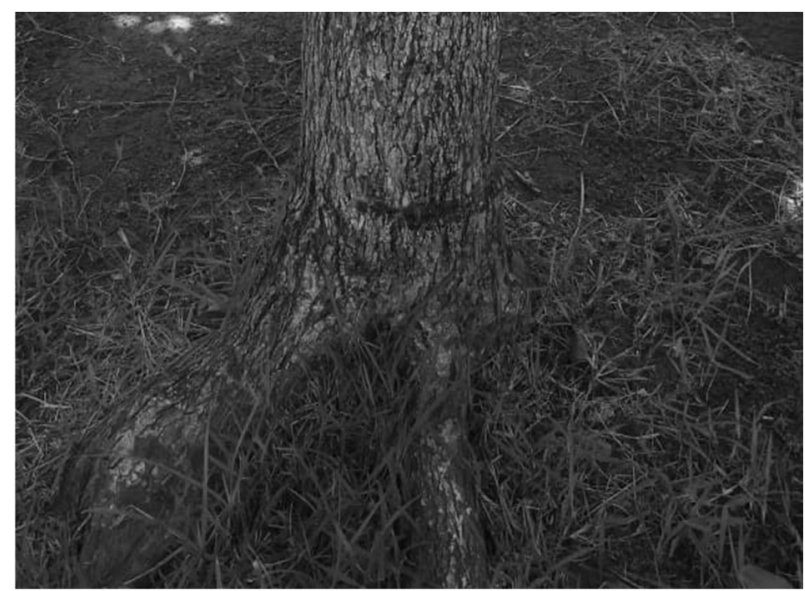

Figura 2: Raízes da espécie Andira parvifolia com afloramentos contidos sem causar danos à Praça das Flores.

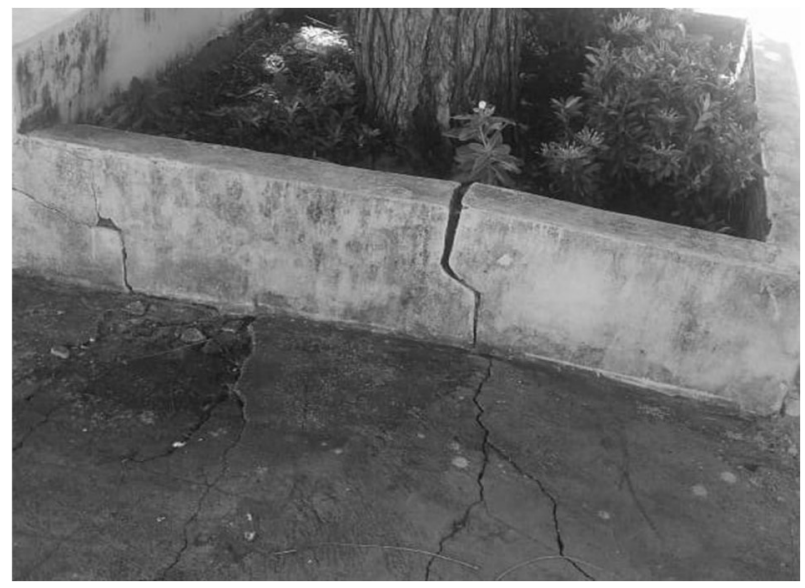

Figura 3: Raízes da espécie Azadirachta indica com afloramentos contidos causando danos à calçada da Praça de Nossa Senhora das Graças.

De forma geral, poucas árvores encontraram-se com o fuste direcionado à rua ou residências em ambas as praças. Esse comportamento só não foi encontrado para 5,55\% dos indivíduos da praça 1, que estavam com o caule posicionados na rua. Quanto à sanidade do fuste, nas duas praças estudadas todas as espécies se encontravam com um fuste saudável.

Em relação a posição das raízes das árvores, 33,33\% das que estavam localizadas na praça 1 apresentaram raízes com afloramentos contidos, sem causar prejuízos às calçadas, sendo todas estas da espécies de alvineira (Figura 2). Já na segunda praça, uma espécie de nim apresentou raízes causando rachaduras nas calçadas (Figura 3), o que pode ser um reflexo da inadequação da espécie para a arborização urbana. Por outro lado, quanto à sanidade das raízes, em ambas as praças as espécies se encontravam saudáveis. 


\section{Diagnóstico da ocorrência de cupins Sanidade das árvores}

De acordo com o levantamento em campo, todas as árvores em ambas as praças apresentaram fissuras naturais na casca. Segundo o manual de recomendações técnicas feito pela SEMAM (2013), fissuras nos troncos e podas deixam a planta susceptível ao ataque de cupins, dessa forma, percebe-se que as árvores das praças estudas apresentam possibilidade de ataque desses organismos.

Quanto aos diferente níveis de podas executadas, na Praça das Flores, 60\% das árvores apresentaram poda leve, 30\% poda intermediária e 10\% poda drástica. Já na Praça Nossa Senhora das Graças, constatouse apenas poda leve e poda média em proporções iguais. Jorge et al. (2017), em seu estudo também encontrou sinais de podas mal executada em área urbana. Os níveis de poda médios podem deixar a planta susceptível ao ataque de cupins, insetos e doenças, além de colocar as espécies em risco o tombamento (AMARAL, 2002; SANTOS et al., 2015).

No entanto, apesar de ambas as praças apresentarem-se susceptível ao ataque de térmitas as mesmas apresentaram-se sadias, sem vestígio e presença de organismos degradadores. Em relação a adequação do espaço, na praça Nossa Senhora das Graças, mais de 60\% dos indivíduos estavam inseridos em espaço adequado, entretanto, na Praça das Flores, metade da vegetação se encontrava em espaço inadequado conforme mostra a Figura 4. De acordo com Cayres et al. (2017), árvores inseridas em espaços inadequados acarretam em incidência de afloramento de raízes, visto que a área permeável é reduzida e as raízes buscam espaço para seu desenvolvimento, muitas das vezes ocasionando prejuízos a calçadas.

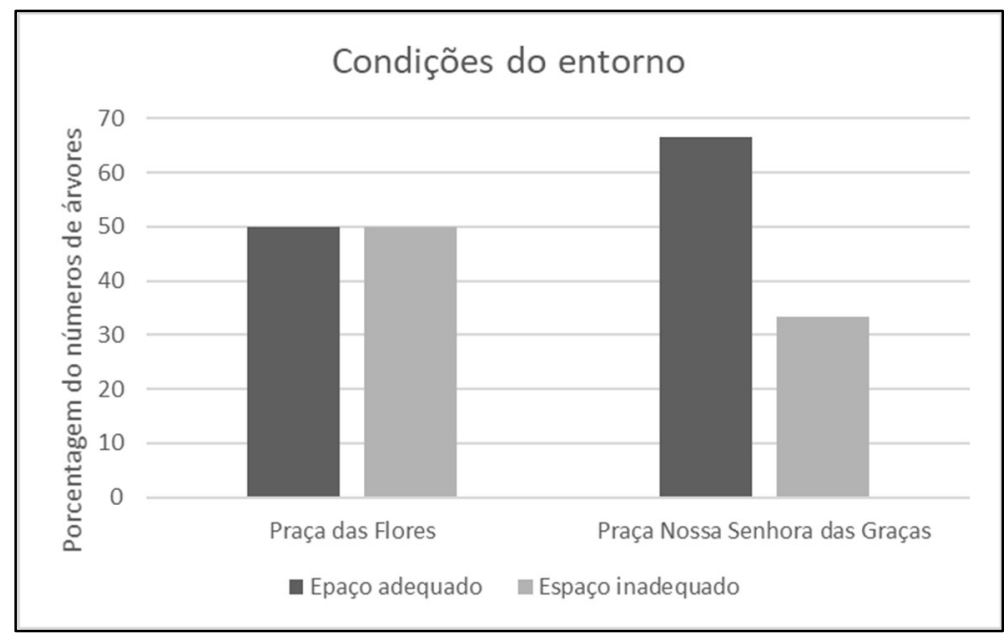

Figura 4: Condições do entorno de ambas as praças.

\section{CONCLUSÕES}

As praças avaliadas ultrapassaram a frequência recomendada por espécies na urbanização urbana, evidenciando a falta de planejamento da silvicultura da cidade de Santarém nestes locais. Além disso, notouse que ambas as praças apresentaram baixa diversidade de espécies, evidenciando justamente a alta frequência das espécies encontradas nas praças. Podendo tal situação ser contornada por plantio de diversidade nas praças.

As árvores de ambas as praças apresentaram condições sadias, não havendo vestígios da presença 
de térmitas nos indivíduos. No entanto, constatou-se fissuras e podas em todos as árvores, o que torna a planta vulnerável a possíveis ataques futuros de cupins, fungos e doenças. Neste contexto, recomenda-se a prática de vistorias de forma frequente nas praças da cidade, afim de diminuir a probabilidade de ataques de xilófagos e acidentes devido à queda de galhos e árvores.

\section{REFERÊNCIAS}

AMARAL, R. D. A. M.. Diagnóstico da ocorrência de cupins xilófagos em árvores urbanas do bairro de Higienópolis, na cidade de São Paulo. Dissertação (Mestrado em Recursos Florestais) - Universidade de São Paulo, Piracicaba, 2002.

BARBOSA, W. S.; FREITAS, R. M.; AZEREDO, J. F. A.; MORAES, T.; GALDI, A. A.. Inventário qualiquantitativo da vegetação arbórea em duas ruas do bairro Espinheiro, Recife/PE. In: ENCONTRO NACIONAL, 8; ENCONTRO LATINO-AMERICANO DE CONFORTO NO AMBIENTE CONSTRUÍDO, 11. Anais. Campinas: ENCAC; ALACAC, 2015.

BENATTI, D. P.; TONELLO, K. C.; JÚNIOR, F. C. A.; SILVA, J. M. S.; OLIVEIRA, I. R.; ROLIM, E. N.; FERRAZ, D. L.. Inventário arbóreo-urbano do município de Salto de Pirapora, SP. Revista Árvore, Viçosa, v.36, n.5, p.887-894, 2012.

CARVALHO, L. A.; NOGUEIRA, J. F.; LEMOS, J. R.. Inventário da arborização de um bairro da cidade de Parnaíba-Piauí, com utilização de informação geográfica. Revista Casa da Geografia de Sobral, Sobral, v.18, n.1, p.100-117, 2016.

CAYRES, T. F. F. F.; MANNIGEL, A. R.; FILHO, E. S.; YAMAGUCHI, N. U.; PACCOLA, E. A. S.. Áreas verdes urbanas: um estudo de caso. Enciclopédia Biosfera, Goiânia, v.14 n.25, 2017.

FREITAS, W. K. de; PINHEIRO, M. A. S.; ABRAHÃO, L. L. F.. Análise da Arborização de Quatro Praças no Bairro da Tijuca, RJ, Brasil. Floresta e Ambiente, v.22, n.1, p.23-31, 2015.

GOMES, E. M. C.; RODRIGUES, D. M. S.; SANTOS, J. T.; BARBOSA, E. J.. Análise quali-quantitativa da arborização de uma praça urbana do Norte do Brasil. Nativa, Sinop, v.4, n.3, p.179-186, 2016.

IBGE. Instituto Brasileiro de Geografia e Estatística. Brasil em Síntese. Rio de Janeiro: IBGE, 2018.

JORGE, V. C.; FILHO, O. E.; MAMEDE, J. S. S.; NASCIMENTO, D. A.; SOUZA, M. S.; JUNIOR, J. G. S.; DORVAL, A.

Diagnóstico fitossanitário da arborização urbana no bairro Cidade Alta, Cuiabá Mato Grosso, Brasil. Revista Espacios, v.38, n.41, 2017.

LINDENMAIER, D. S.; SANTOS, N. O.. Arborização urbana das praças de Cachoeira do Sul, RS, Brasil: fitogeografia, diversidade e índice de áreas verdes. Revista Pesquisas botânicas, n.59, p.208-319, 2008.

MENDES, A. S.; ALVES, M. V. S.. A degradação da madeira e sua preservação. Brasília: Instituto Brasileiro de Desenvolvimento Florestal, 1988.
MILANO, M. S.; DALCIN, E. C.. Arborização de vias públicas. Rio de Janeiro: Light, 2000.

OLIVEIRA, A. S.; NOGUEIRA, M. C. J. A; SANCHES, L. NOGUEIRA, J. S.. Variáveis meteorológicas e cobertura vegetal de espécies arbóreas em praças urbanas em Cuiabá, Brasil. Revista Brasileira de Meteorologia, Cuiabá, v.28, n.4, p.389-400, 2013.

OLIVEIRA, A. S.; SANTOS, F. M. M.; FRANCO, F. M.; DURANTE, L. C.; CALLEJAS, I. J. A.; NOGUEIRA, M. C. J. A.. Estudo da cobertura vegetal arbórea em praças urbanasCuiabá/Brasil. In: ENCONTRO LATINO AMERICANO DE CONFORTO NO AMBIENTE CONSTRUIDO, 7. Anais. Búzios: ELACAC, 2011.

SANTARÉM. Portal da Prefeitura de Santarém. Santarém, 2019.

REMADE. Principais agentes deterioradores de madeira. Revista Remade, Curitiba, n.134, 2013.

SCHALLENBERGER, L. S.; ARAUJO, A. J.; ARAUJO, M. N. DEINER, L. J.; MACHADO, G. O.. Avaliação da condição de árvores urbanas nos principais parques e praças do município de Irati/PR. Revista da Sociedade Brasileira de Arborização Urbana, Piracicaba, v.5, n.2, p.105-123, 2010.

SCHURCH, M. I. S.. Arborização urbana: uma contribuição à qualidade de vida com uso de geotecnologias. Rio Grande do Sul. Dissertação (Mestrado em geométrica) - Universidade Federal de Santa Maria, Santa Maria, 2006.

SEMAM. Secretaria de Meio Ambiente. Manual de recomendações técnicas para projetos de arborização urbana e procedimentos de poda. Aracruz: SEMAM, 2013.

SILVA, C. D. D.; ALMEIDA, L. M.. Composição florística e fitossociológica das praças do bairro de Neópolis, NatalRN. Carpe Diem: Revista Cultural e Científica do UNIFACEX, v.14, n.2, p.86-103, 2016

SOUSA, S. F.. Eficiência dos óleos de andiroba, copaíba e pinhão manso na melhoria da resistência da madeira de pinus elliottii a organismos xilófagos. 2016.

TAKEDA, I. J. M.; BOTARI, J. C.; BOTARI, A.. Levantamento da vegetação de praças representativas do município de Umuarama/PR. In: SAFETY, HEALTH AND ENVIRONMENT WORLD CONGRESS, 8. Anais. Lisboa, 2013. p.353-357.

TISCHER, J. C.; FORTE, A. R.; MORAES, C. P.. Análise qualiquantitativa de indivíduos arbóreos das praças centrais do município de Leme, SP. REVSBAU, v.9, n.3, p.49-64, 2015.

A CBPC - Companhia Brasileira de Produção Científica (CNPJ: 11.221.422/0001-03) detém os direitos materiais desta publicação. Os direitos referem-se à publicação do trabalho em qualquer parte do mundo, incluindo os direitos às renovações, expansões e disseminações da contribuição, bem como outros direitos subsidiários. Todos os trabalhos publicados eletronicamente poderão posteriormente ser publicados em coletâneas impressas sob coordenação da Sustenere Publishing, da Companhia Brasileira de Produção Científica e seus parceiros autorizados. Os (as) autores (as) preservam os direitos autorais, mas não têm permissão para a publicação da contribuição em outro meio, impresso ou digital, em português ou em tradução. 